\title{
Effect of Different LED Light-curing Units on Degree of Conversion and Microhardness of Bulk-fill Composite Resin
}

\author{
Juliana S Siagian ${ }^{1}$, Dennis Dennis², Tulus Ikhsan ${ }^{3}$, Trimurni Abidin ${ }^{4}$
}

\begin{abstract}
Aim: The aim of this study is to compare the effect of the use of second-generation and third-generation LED light-curing units (LCUs) on the degree of conversion (DC) and microhardness (VHN) of bulk-fill resin composites.

Materials and methods: Thirty cylindrical specimens (each $n=5$ ) of Tetric N-Ceram Bulk-Fill, Filtek ${ }^{\mathrm{TM}}$ Bulk-Fill Posterior Restorative, and SDR flow were prepared in metal molds ( $5 \mathrm{~mm}$ in diameter and $4 \mathrm{~mm}$ in thickness) and cured with second-generation LED (SmartLite ${ }^{\oplus}$ Focus ${ }^{\oplus}$, Dentsply Sirona) and third-generation LED (Bluephase ${ }^{\oplus}$ style, Ivoclar Vivadent) resulting in six groups. Degree of conversion was determined using Fourier transform infrared spectroscopy (FTIR), and microhardness with Vickers microhardness tester. Data were statistically analyzed using one-way ANOVA and least significance difference (LSD) test, and DC and microhardness were correlated using Pearson's correlation ( $\alpha=0.05)$.

Results: There was a significant difference between DC and VHN between all groups of bulk-fill which were cured by second-generation LED curing light and third-generation LED curing light. Then there is no significant difference between DC of the three composite bulk-fill resins by (second-generation LED vs third-generation LED curing light).

Conclusion: The second-generation LED curing light can still be used to cure bulk-fill resin composites by increasing the duration of irradiation. Clinical significance: In the microhardness test, there was a significant difference in the Filtek ${ }^{\mathrm{TM}}$ Bulk-Fill Posterior Restorative resin composites. Keywords: Bulk-fill composite resin, Degree of conversion, LED light-curing unit, Microhardness.

The Journal of Contemporary Dental Practice (2020): 10.5005/jp-journals-10024-2848
\end{abstract}

\section{INTRODUCTION}

Composite resins in dentistry are increasingly popular and become the material of choice for direct and indirect restorations for both anterior and posterior teeth due to esthetic properties, good mechanical properties, and low cytotoxicity. ${ }^{1}$ The main problem often encountered in composite resin stacks is incomplete polymerization. The degree of polymerization is defined as the presence of residual monomers due to inadequate polymerization. Inadequate polymerization can produce high residual monomers which can irritate pulp tissue, stimulate bacterial growth, and ultimately affect the success of restoration in the clinic. ${ }^{2}$ The degree of polymer composite resin polymerization appears to be influenced by intrinsic and extrinsic factors. ${ }^{3}$ Intrinsic factors include composition of composite resin material, organic material (matrix), inorganic (type and content of filler material), viscosity, and thickness of composite resin layer. Extrinsic factors include lightcuring unit (LCU), intensity and timing of light exposure, methods of visible light activation, and temperature. ${ }^{3,4}$

There are several disadvantages associated with the layering technique in the conventional composite, such as bonding failure between the layers, contamination between composite layers, limitation to access in the small cavities leading to difficulty in placement, increased time consumption including placement of the composite in increments and curing it. ${ }^{5}$

Bulk-fill composite resin materials have been introduced to overcome these disadvantages. Bulk-fill composite resin can be cured with thicknesses of up to $4-5 \mathrm{~mm} .{ }^{6,7}$ The bulk-fill is more transparent, so the light transmission from the light-curing unit can pass through the entire composite resin thickness. Another advantage of bulk-fill composite resin is that it is easy to apply, saves time, does not form voids, has low polymerization shrinkage, thereby reducing micro-leakage, and reducing shrinkage pressure
1,2,4 Department of Conservative Dentistry, Faculty of Dentistry, Universitas Sumatera Utara, Medan, Indonesia

${ }^{3}$ Physics Department, Faculty of Mathematics and Science, Universitas Sumatera Utara, Medan, Indonesia

Corresponding Author: Dennis Dennis, Department of Conservative Dentistry, Faculty of Dentistry, Universitas Sumatera Utara, Medan, Indonesia, Phone: +62 8126555068, e-mail: dennis@usu.ac.id

How to cite this article: Siagian JS, Dennis D, Ikhsan T, et al. Effect of Different LED Light-curing Units on Degree of Conversion and Microhardness of Bulk-fill Composite Resin. J Contemp Dent Pract 2020;21(6):615-620.

Source of support: Nil

Conflict of interest: None

because it has high elasticity. ${ }^{6,8,9}$ Bulk-fill RBCs can be categorized as high viscosity or low viscosity, light or dual cured. 6,10

Efficient polymerization requires an appropriate wavelength to maximize photoinitiator absorption, and photoactivation of composite resin must receive appropriate total energy $\left(\mathrm{J} / \mathrm{cm}^{2}\right)$. The light quality produced by light-curing units (LCUs) directly influences the polymerization of restorative materials and is highly dependent on the intensity or strength of irradiation. ${ }^{4,11}$ The types of light-curing units that are often used include light-emitting diodes (LEDs), halogen quartz tungsten (QTH), plasma arc curing (PAC), and argon laser lamps. ${ }^{12}$

LED LCUs are becoming increasingly popular in dental practice. The advantage of using LED technology for polymerization of this material is that it includes a moderate price, increased light intensity on second-generation LEDs, which allows a reduction in the duration of irradiation, practical and long duration of use for diode lamps of around 1000 hours. ${ }^{13}$ 
First-generation LED LCUs use silicon carbide with a power output of $7 \mu \mathrm{W}$, composed of 7-19 diodes, low irradiance levels around $100-280 \mathrm{~mW} / \mathrm{cm}^{2}$ which takes a long time for radiation up to 60 seconds for a material thickness of $2 \mathrm{~mm}$. It has a very narrow spectrum in the ideal range for composite resins with photoinitiator camphorquinone (CQ). First-generation LED cannot polymerize composite resins such as QTH, because the first-generation LED spectrum output is only concentrated in the blue wavelength range. $^{12,14}$

The second-generation LED LCUs are made using the technology of gallium nitrite with a larger power output of $3 \mathrm{~mW}$ and irradiance of $800 \mathrm{~mW} / \mathrm{cm}^{2}$ and can reach $1000 \mathrm{~mW} / \mathrm{cm}^{2}$. The second-generation LED LCUs are also proved to produce polymeric material properties comparable to QTH and the potential for reduction in curing time without loss of material properties. The second-generation LEDs have problems with temperature in the chip, so they have a heat sink to remove the heat from the chip. ${ }^{12,14}$

Third-generation LED LCUs with irradiance starting from $1000 \mathrm{~mW} / \mathrm{cm}^{2}$ to nearly $3000 \mathrm{~mW} / \mathrm{cm}^{2}$ are not only effective for CQ photoinitiators, but also for other alternative photoinitiators because they emit more than one wavelength of light, also called polywave or multipeak. ${ }^{14}$

The value of microhardness for composite resin material can determine the degree of polymerization, so it is very useful to know the microhardness of the material if the material is used in the clinic. ${ }^{15}$ The polymerization will determine the percentage change in monomer double bonds into a single polymeric bond known as the degree of conversion. ${ }^{3}$ The degree of conversion is a key measure of the effectiveness of polymerization and crosslinking of the monomers used to form resins.

This study aims to compare the effect of the use of secondgeneration and third-generation LED curing light on the degree of conversion and microhardness of bulk-fill resin composite.

\section{Materials and Methods}

This study was performed at experimental laboratory, Universitas Sumatera Utara, Medan, Indonesia. Three types of composite materials: Filtek Bulk-Fill (FB; 3M ESPE, Saint Paul, MN, USA), Tetric $\mathrm{N}$-Ceram Bulk-Fill (TB; Ivoclar Vivadent, Zurich, Switzerland), and SDR (Dentsply, Konstanz, Germany), were used for the study (Table 1). Thirty cylindrical specimens with size $5 \mathrm{~mm}$ in diameter $x$ $4 \mathrm{~mm}$ in thickness of each tested material were prepared in a metal mold. Specimens were divided into six groups by filling metal mold placed on a celluloid strip and a glass slide. Each sample was then covered by another celluloid strip. The sample was given pressure of $1 \mathrm{~kg}$ load to extrude excess material. The samples were lightcured for 20 seconds using second-generation LED curing light
(SmartLite ${ }^{\circledast}$ Focus $^{\circledast}$, Dentsply Sirona) and 40 seconds using thirdgeneration LED curing light (Bluephase ${ }^{\circledast}$ style, Ivoclar Vivadent).

Specimens were divided into six groups, namely groups I, II, and III which were cured with second-generation LED curing light (SmartLite ${ }^{\circledR}$ Focus $^{\circledast}$, Dentsply Sirona) and groups IV, V, and VI which were cured with third-generation LED curing light (Bluephase ${ }^{\circledast}$ style, Ivoclar Vivadent). There were three tested materials used in this study, i.e., Tetric N-Ceram Bulk-Fill (groups I and IV), SDR flowable (groups II and V) and Filtek ${ }^{\mathrm{TM}}$ Bulk-Fill Posterior Restorative (groups III and VI) with the light tip in contact with the Mylar strip. Then the samples were immersed in distilled water solution in plastic vials and stored in an incubator at $37^{\circ} \mathrm{C}$ for 24 hours. Degree of conversion (DC) was determined using Fourier transform infrared spectroscopy (FTIR), and microhardness was tested with Vickers microhardness tester.

\section{Degree of Conversion Analysis}

Fourier transform infrared spectroscopy (FTIR) examination was performed to investigate the degree of conversion. Each of the specimens $(n=5)$ of each composite resin material was milled into a fine powder with a mortar and pestle. Ten milligrams of the composite resin powder was mixed with $10 \mathrm{mg}$ of potassium bromide powder and pressed to produce a thin disk. After that the specimens were kept in a specimen holder and transferred to the spectrophotometer. The absorbance peaks were observed and recorded using the diffuse reflection mode of FTIR with 45 scans, at a wavelength of $450-4000 \mathrm{~cm}^{-1}$ and a resolution of $4 \mathrm{~cm}^{-1}$.

Unpolymerized specimens of each composite resin material were smeared onto thin potassium bromide disks, then they were put into a cell holder in spectrophotometer, and then a spectrum was observed with the same parameters as for the polymerized specimens.

Degree of conversion was determined by estimating the changes in peak height ratio of the absorbance intensities of aliphatic $C=C$ peak at $1638 \mathrm{~cm}^{-1}$ and that of an internal standard peak of aromatic $\mathrm{C}=\mathrm{C}$ at $1608 \mathrm{~cm}^{-1}$ during polymerization, in relation to the uncured material. DC\% for each specimen was calculated using the following equation:

$$
\text { DC } \%=\left\{\frac{1-\left(1638 \mathrm{~cm}^{-1} / 1608 \mathrm{~cm}^{-1}\right) \text { cured }}{\left(1638 \mathrm{~cm}^{-1} / 1608 \mathrm{~cm}^{-1}\right) \text { uncured }}\right\} \times 100 \%
$$

\section{Vickers Hardness Test}

The Vickers hardness number (VHN) of each specimen was investigated on the top and the bottom surfaces using a microhardness testing machine. The machine was also equipped with a diamond pyramidal microindenter to apply a load of $300 \mathrm{~g}$ for 15 seconds. Each surface of the specimen (top and bottom) was

Table 1: Summary of the resin composite products used in the study

\begin{tabular}{|c|c|c|c|c|c|c|}
\hline $\begin{array}{l}\text { Material, } \\
\text { abbreviation }\end{array}$ & Category & Resin matrix & Main fillers & $\begin{array}{l}\text { Filler load } \\
\text { (wt\%/vol\%) }\end{array}$ & Photoinitiator & Manufacturer \\
\hline Filtek Bulk-Fill (FB) & $\begin{array}{l}\text { Nano-hybrid bulk- } \\
\text { fill composite }\end{array}$ & $\begin{array}{l}\text { AUDMA, UDMA, } \\
\text { DDDMA }\end{array}$ & $\begin{array}{l}\text { Silane-treated } \\
\text { ceramics, silica, } \\
\text { zirconia }\end{array}$ & $77 / 59$ & $\mathrm{CQ}$ & $\begin{array}{l}\text { 3M ESPE, Dental } \\
\text { products, Saint } \\
\text { Paul, MN, USA }\end{array}$ \\
\hline $\begin{array}{l}\text { Tetric N-Ceram } \\
\text { Bulk-Fill (TB) }\end{array}$ & $\begin{array}{l}\text { Nano-hybrid bulk- } \\
\text { fill composite }\end{array}$ & $\begin{array}{l}\text { Bis-GMA, Bis-EMA, } \\
\text { UDMA }\end{array}$ & $\begin{array}{l}\text { Barium glass, } \\
\text { silicate glass }\end{array}$ & $81 / 61$ & 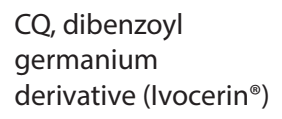 & $\begin{array}{l}\text { Ivoclar Vivadent, } \\
\text { Zurich, Switzerland }\end{array}$ \\
\hline SDR flow (SDR) & $\begin{array}{l}\text { Bulk-fill flowable } \\
\text { composite }\end{array}$ & $\begin{array}{l}\text { Bis-EMA, modified } \\
\text { UDMA, TEGDMA }\end{array}$ & $\begin{array}{l}\text { Barium-aluminum } \\
\text { fluorosilicate glass }\end{array}$ & $68 / 45$ & $\mathrm{CQ}$ & $\begin{array}{l}\text { Dentsply, Konstanz, } \\
\text { Germany }\end{array}$ \\
\hline
\end{tabular}


divided into five quadrants; one indentation took place for each quadrant. The VHN for each surface was recorded as the mean of the five readings.

\section{Statistical Analyses}

The data for DC and VHN were statistically analyzed with one-way ANOVA and least significance difference (LSD) test. Correlations between VHN and DC were indicated by Pearson's correlation test. $p$ value $\leq 0.05$ was considered to be statistically significant in all tests.

\section{Results}

\section{Degree of Conversion}

The mean value of DC in all groups is presented in Table 2 and Figure 1. The highest mean value of DC was found in Filtek ${ }^{\mathrm{TM}}$ Bulk-Fill composite resin cured by third-generation LED light-curing units: $60.92 \pm 10.83 \%$. The lowest mean value of DC was found in bulk-fill SDR composite resins which were cured by second-generation LED curing units: $32.24 \pm 8.00 \%$.

One-way ANOVA revealed a statistically significant difference in DC among the materials tested $(p<0.05)$.

The next step is the least significance difference (LSD) test. LSD test results are presented in Table 2 .

The LSD test showed there was no significant difference in the degree of conversion between bulk-fill composite resin cured by second-generation LED light-curing units and that cured by thirdgeneration LED light-curing units (as shown in Table 3).

\section{Vickers Microhardness Number}

The mean value of microhardness in all groups is presented in Table 4. The surface of the sample in group III showed the highest

Table 2: Mean value and standard deviation of DC of composite bulkfill (\%)

\begin{tabular}{lc}
\hline Group & Mean \pm SD \\
\hline I & $58.02 \pm 9.08$ \\
II & $32.24 \pm 8.00$ \\
III & $56.18 \pm 9.16$ \\
IV & $51.43 \pm 9.52$ \\
V & $41.76 \pm 6.99$ \\
VI & $60.92 \pm 10.83$ \\
\hline
\end{tabular}

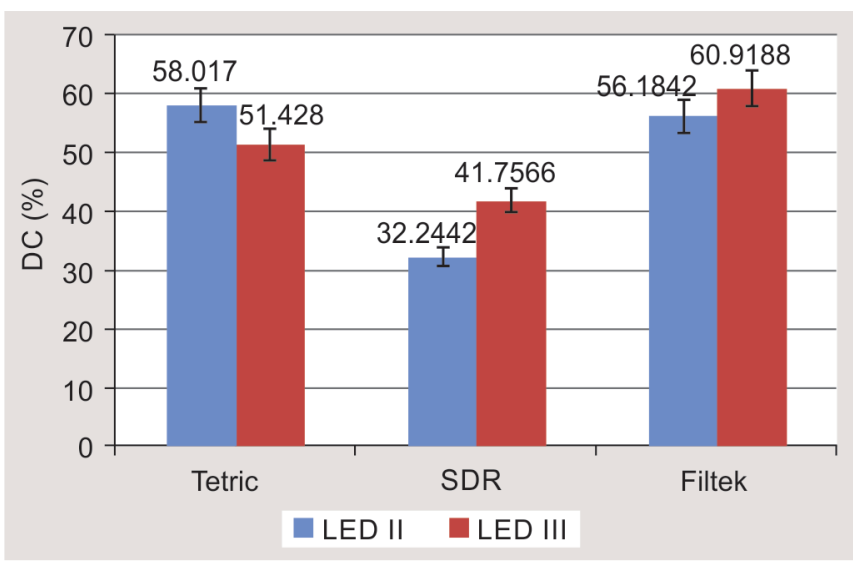

Fig. 1: Mean value of degree of conversion of composite bulk-fill (\%) mean value of microhardness (Posterior Restorative Bulk Fill Filtek composite resin cured by second-generation LED light-curing units) with a value of $69.55 \pm 4.71 \mathrm{VHN}$, and the surface of the sample in group $V$ the lowest mean value (composite resin flowable bulk-fill SDR cured by the third generation of light-curing units) with a value of $36.33 \pm 8.31 \mathrm{VHN}$. At the bottom surface of the sample, the highest mean value of microhardness was seen in group III with a value of $50.99 \pm 3.08 \mathrm{VHN}$ and the lowest mean value was seen in group V with a value of $27.51 \pm 3.56 \mathrm{VHN}$.

One-way ANOVA revealed a statistically significant difference in microhardness among the materials tested $(p<0.05)$.

To see which groups had significant differences between groups, the least significance difference (LSD) test was performed which showed there was a significant difference in the Filtek ${ }^{\mathrm{TM}}$ BulkFill Posterior Restorative resin composites (Tables 5 and 6).

\section{Correlation between VHN and DC}

No significant correlation was found between $D C$ and $\mathrm{VHN}$ results as indicated by regression analysis $(r=0.245, p=0.640)$. This correlation is also shown in Table 7.

Table 3: Least significance difference (LSD) test for the degree of conversion between groups on second- and third-generation LEDs

\begin{tabular}{|c|c|c|c|c|c|c|}
\hline \multirow[b]{3}{*}{ Group } & \multicolumn{6}{|c|}{ LSD test } \\
\hline & \multicolumn{3}{|c|}{ LED II } & \multicolumn{3}{|c|}{ LED III } \\
\hline & 1 & II & III & IV & $V$ & $V I$ \\
\hline 1 & & $0.000^{*}$ & 0.750 & 0.259 & $0.009^{*}$ & 0.615 \\
\hline II & & & $0.000^{*}$ & $0.003^{*}$ & 0.108 & $0.000^{*}$ \\
\hline III & & & & 0.412 & $0.018^{*}$ & 0.414 \\
\hline IV & & & & & 0.103 & 0.109 \\
\hline V & & & & & & $0.003^{*}$ \\
\hline
\end{tabular}

*Significant difference $p<0.05$

Table 4: Microhardness mean and standard deviation of the materials

\begin{tabular}{lll}
\hline & Mean \pm SD & Mean \pm SD \\
\cline { 2 - 3 } Group & Top surface & Bottom surface \\
\hline I & $51.64 \pm 6.47$ & $33.25 \pm 2.12$ \\
II & $36.68 \pm 2.58$ & $28.85 \pm 1.99$ \\
III & $69.55 \pm 4.71$ & $50.99 \pm 3.08$ \\
IV & $58.30 \pm 7.70$ & $32.84 \pm 5.03$ \\
V & $36.33 \pm 8.31$ & $27.51 \pm 3.56$ \\
VI & $51.10 \pm 1.26$ & $35.47 \pm 4.29$ \\
\hline
\end{tabular}

Table 5: Least significance difference (LSD) test for the VHN between groups on second- and third-generation LEDs on top surface

\begin{tabular}{llllllll}
\hline & \multicolumn{5}{c}{ LSD test ( $p$ value) } \\
\cline { 2 - 3 } \cline { 5 - 7 } Group & I & II & III & & \multicolumn{4}{c}{ LED III } \\
\hline I I & 0.059 & 0.000 & & 0.0853 & 0.016 & 0.329 \\
II & & & 0.000 & & 0.086 & 0.553 & 0.007 \\
III & & & & & 0.000 & 0.000 & $0.000^{*}$ \\
IV & & & & & 0.025 & 0.249 \\
V & & & & & & 0.002 \\
\hline
\end{tabular}

Note: Groups I and IV (Tetric N-Ceram Bulk-Fill), groups II and V (flowable SDR), and groups III and VI (Posterior Restorative Bulk-Fill Philosophy). LED II vs LED III. *Significant difference $p<0.05$ 
Table 6: Least significance difference (LSD) test for the vickers hardness number between groups on second- and third-generation LEDs on bottom surface

\begin{tabular}{|c|c|c|c|c|c|c|}
\hline \multirow[b]{3}{*}{ Group } & \multicolumn{6}{|c|}{ LSD test ( $p$ value) } \\
\hline & \multicolumn{3}{|c|}{$L E D \|$} & \multicolumn{3}{|c|}{ LED III } \\
\hline & I & II & III & IV & V & VI \\
\hline I & & 0.000 & 0.000 & 0.081 & 0.000 & 0.884 \\
\hline II & & & 0.000 & 0.000 & 0.924 & 0.001 \\
\hline III & & & & 0.005 & 0.000 & $0.000^{*}$ \\
\hline IV & & & & & 0.000 & 0.061 \\
\hline V & & & & & & 0.000 \\
\hline
\end{tabular}

Note: Groups I and IV (Tetric N-Ceram Bulk-Fill), groups II and V (flowable SDR), and groups III and VI (posterior restorative bulk-fill philosophy). LED II vs LED III. *Significant difference $p<0.05$

Table 7: Correlation value between degree of conversion (DC) and Vickers hardness number (VHN)

\begin{tabular}{lll}
\hline & $r$ & $p$ value \\
\hline DC and VHN & 0.245 & 0.640 \\
\hline
\end{tabular}

\section{Discussion}

The physical and mechanical properties of dental composites are directly influenced by the degree of conversion achieved during polymerization. The degree of conversion and microhardness are considered as important physical properties of composite resins and play an important role in comparing and characterizing restoration materials. $^{13,15}$

Composite resins with high degree of conversion value have greater mechanical properties, greater wear resistance, better color stability and are more biocompatible so that they contribute to the longevity of composite resins. ${ }^{16}$

Surface microhardness and depth of cure are considered to be important physical properties of resin composites and play a significant role in comparing and characterizing dental restorative materials. Microhardness is commonly used for the evaluation of the depth of cure and, thus, also the efficiency of the curing lights. ${ }^{17}$

There are many factors that affect photopolymerization: extrinsic factors which include method of light-curing, light spectrum, light guide tip positioning, and irradiation protocols, and intrinsic factors which include filler content including the percentage and the size, photoinitiator type, comonomer composition and ratio. ${ }^{3}$

The results of this study are shown in Table 2, which shows that the highest mean DC value was seen in group VI with a value of $60.92 \pm 10.83 \%$ (Filtek ${ }^{\mathrm{TM}}$ Bulk-Fill Posterior Restorative cured by third-generation LED LCUs), while the lowest mean DC value was seen in group II (flowable composite bulk SDR resin illuminated by second-generation LED LCUs) with a value of $32.24 \pm 8.00 \%$. The order of value of degree of conversion is Posterior Restorative Bulk-Fill Filtek > Tetric N-Ceram > flowable SDR.

Many factors influence composite resin polymerization, such as composite resin composition, number and size of particle filler, type of photoinitiator, spectral output emitted by light-curing unit (LCU), light intensity given by light-curing unit to polymer (power density), length of irradiation, the total amount of light transmitted by LCU (energy density), and the distance between the light-curing unit, composite resin and shades. ${ }^{12,18,19}$ The most important factors affecting the mechanical properties of composite resins are the composition of the composite resin itself and the curing depth. ${ }^{20}$
This is probably due to differences in material composition, the highest DC value is in Bulk-Fill Posterior Restorative Filtek because this composite has a greater percentage of filler based on its weight of $76.5 \% /(58.4 \%)$ and Bulk-Fill Posterior Restorative Filtek having a combination of several monomers in the matrix such as UDMA, BisGMA, AUDMA, AFM, DDMA which can reduce volumetric shrinkage and stiffness of the polymer matrix, also can increase the degree of conversion, as well as Tetric N-Ceram Bulk-Fill using another additional photoinitiator which is Ivocerin. The flowable SDR has a lower polymer network or filler content density of $68 \% /(45 \%)$ so that it is included in bulk-fill flowable with low viscosity, in contrast to the Bulk-Fill Posterior Restorative Filtek and Tetric N-Ceram which are included in the composite group high bulk viscosity fill.

The difference of DC between the bulk-fill which was cured by second-generation LED and third-generation LED from the LSD test results showed no effect on the use of second-generation LED LCUs compared to third-generation LED LCUs to the degree of conversion of composite bulk-fill resin. The value of DC of the three bulk-fill resins in this study was different but not significant.

This probably caused the three composites contain UDMA monomers which are amino groups responsible for specific chain transfer reactions to provide an alternative pathway to continue polymerization. This reaction results in the movement of radical regions faster on the chain structure and results in increased monomer polymerization and conversion, so that high reactivity and conversion rates are achieved with the use of UDMA monomers. ${ }^{21,22}$ There are two main characteristics of monomers that influence the degree of conversion: the viscosity of the monomer and the flexibility of its own chemical structure. ${ }^{23}$ Some studies proved that the highest degree of conversion of various sequence monomer systems is as follows: Bis-GMA $<$ Bis-EMA $<$ UDMA $<$ TEGDMA. ${ }^{24}$ Papadogiannis et al. also reported that the highest degree of conversion was found in bulk-fill composite resins containing UDMA and TEGMA without Bis-GMA. This happens because UDMA has a lower viscosity than Bis-GMA. ${ }^{25}$

There is also possibility that causes the $D C$ in this study shows no significant difference between the three bulk-fill which were cured by second-generation LED compared to third-generation LED lightcuring are due to the total energy transmitted by the light-curing. It has also been studied that the degree of conversion is affected by total light energy. Energy is obtained from the intensity of light multiplied by the time of exposure to light. ${ }^{17}$

In the current study, the two tested LCUs have similar performance resulting in comparable Vickers hardness number and degree of conversion in all three tested materials. These findings may be explained by the fact that the irradiance between the two LCUs is not much different. Besides, total energy values and maximum emission peaks have not much discrepancy. There was no difference in distribution of energy delivered at wavelengths 380-420 nm and 420-540 nm. They did not affect the tested material properties. With various brands and shades, the total energy required for a $2-\mathrm{mm}$ increment of dental resin has been reported to range from 6 to $24 \mathrm{~J} / \mathrm{cm}^{2}$.

In the present study, the third-generation LED has an intensity of $1200 \mathrm{~mW} / \mathrm{cm}^{2}$ with an irradiation time of 20 seconds. The mean total energy for the third-generation LED group is $24 \mathrm{~J} / \mathrm{cm}^{2}$. For the second-generation LED group, the intensity is $1000 \mathrm{~mW} / \mathrm{cm}^{2}$, the irradiation time is 40 seconds, and then it has a greater total energy that is $40 \mathrm{~J} / \mathrm{cm}^{2}$.

In addition, as reported by $\mathrm{Al}$-ahdal et al., the most common strategy for maximizing $D C$ and minimizing the release of 
monomers is to provide sufficient energy for polymerization by increasing irradiation time. ${ }^{21}$ Several studies have stated that the duration of irradiation can affect polymerization because the longer the duration of irradiation, the more the monomers that are polymerized. Previous studies conducted by llie et al. and Zorzin et al. showed that increasing the irradiation duration had a positive impact on DC of bulk-fill composite resins, so the addition of duration was suggested by researchers for the application of composite resins to deep cavities. ${ }^{26,27}$

The microhardness value which was obtained in the present study on the top surface of bulk-fill composite resin material specimens was higher compared to the bottom surface in all experimental groups. This finding might be due to the reduction in light as it penetrates through the composite material or may be due to light scattered through the filler particles. ${ }^{28}$

On the top and button surfaces, the composites Filtek ${ }^{\text {TM }}$ Bulk-Fill Posterior Restorative and Tetric N-Ceram irradiated with secondgeneration and third-generation LED LCUs show significantly higher microhardness values compared to the flowable SDR bulk-fill. This shows that the conventional bulk-fill composites have a higher surface hardness than flowable bulk-fill composites. The value of microhardness of Posterior Restorative Bulk-Fill Filtek ${ }^{\mathrm{TM}}$ composite is greater than that of Tetric N-Ceram Bulk-Fill. This variation in microhardness occurs because the Filtek ${ }^{\mathrm{TM}}$ Bulk-Fill Posterior Restorative and Tetric N-Ceram composite resins contain higher filler particles. Filler level (wt\%)/volume (vol) on Bulk-Fill Posterior Restorative Filtek ${ }^{\mathrm{TM}}$ is $76.5 \% /(58.4 \%)$, on Tetric N-Ceram Bulk-Fill is $75-77 \% /(53-55 \%)$, and on flowable SDR is $68 \% /(45 \%)$.

This result is similar to that of Ilie et al. where SDR exhibited the lowest Vickers hardness values. ${ }^{29}$ Similarly, another study raised a concern regarding the low microhardness values for some bulkfill composites, especially SDR and Filtek Bulk-Fill. ${ }^{26}$ Leprince et al. concluded that some of bulk-fill composites like SDR and Filtek Bulk-Fill displayed very low Vickers microhardness values. ${ }^{9}$ Also, Flury et al. found that SDR showed low hardness values. ${ }^{30}$

There is also possibility that microhardness depends also on other factors such as the type and size of filler particles, and the methodology being tested. In addition, Thomé et al. stated that a higher microhardness value was obtained when the tip of the light source came in contact with the specimen surface. ${ }^{31}$ In addition, Caldas et al. reported that the ideal distance between the end of the light source and the surface of the specimen is $0 \mathrm{~mm}$, that is the tip of the light source is directly in contact with the surface. In this study, the tip of the light source was in contact with the surface of the specimen with only a Mylar strip separating the tip. ${ }^{32}$

The shade of the resin composite can also affect microhardness. According to Thome et al., lighter-colored resins showed higher microhardness values compared to dark-colored ones that require more lighting time to achieve higher hardness values. ${ }^{31}$

In this study, the correlation value is very low, $r=0.245$ and $p$ value $=0.640(p>0.05)$, indicating there was no significant relationship between the degree of conversion and microhardness.

The correlation between DC and VHN was very low, according to the study conducted by Silva et al. ${ }^{33}$ Other studies done by Mandikose et al. and Santos et al. showed a negative correlation between the degree of conversion and microhardness. ${ }^{34,35}$ In other studies, although surface hardness showed good correlation with the degree of conversion in specific composite resins, the hardness value cannot be used to predict the degree of conversion if the composites compared are different. ${ }^{36}$
In this study, the correlation between DC and VHN was very low because there were three types of bulk-fill composite resin used in this current study, i.e., Filtek ${ }^{\mathrm{TM}}$ Bulk-Fill Posterior Restorative and Tetric N-Ceram constitute high viscosity (packable) composite, meanwhile SDR flow constitutes low viscosity (flowable) composite. In addition, the three materials have different amounts and sizes of fillers as well as different types of monomers between each ingredient.

\section{Conclusion}

The results showed that there were significant differences between the value of degree of conversion and microhardness between all groups of bulk-fill composite resins which were cured by thirdgeneration LED LCUs and second-generation LED LCUs. Then there is no significant difference between the values of DC of the three bulk-fill composite resins which are cured by (econd-generation LED vs third-generation LED). But the microhardness test showed that there were significant differences in the Filtek ${ }^{\mathrm{TM}}$ Bulk-Fill Posterior Restorative composite resin. The second-generation LED LCUs can still be used for curing bulk-fill composite resins by increasing the irradiation duration.

\section{References}

1. Gonçalves F, de Paiva Campos LM, Rodrigues-Júnior EC, et al. Comparative study of bulk-fill composites: degree of conversion, post-gel shrinkage and cytotoxicity. Braz Oral Res 2018;32(0):17. DOI: 10.1590/1807-3107bor-2018.vol32.0017.

2. Anusavice KJ, Shen C, dan Rawls HR. Philips' Science of Dental Materials. 12th ed., St. Louis: Elsevier; 2014. pp. 290-295.

3. Leprince JG, Palin WM, Hadis MA, et al. Progress in dimethacrylatebased dental composite technology and curing efficiency. Dent Mater 2013;29(2):493-511. DOI: 10.1016/j.dental.2013.02.001.

4. Wahbi MA, Aalam FA, Fatiny Fl, et al. Characterization of heat emission of light-curing units. Saudi Dent J 2012;24(2):91-98. DOI: 10.1016/j. sdentj.2012.01.003.

5. Alrahlah A, Silikas N, Watts DC. Post-cure depth of bulk fill dental resin composites. Dent Mater 2014;30(2):149-154. DOI: 10.1016/j. dental.2013.10.011.

6. Aldossary M, Roebuck E, Santini A. Bulk fill resin composite materials cured with single-peak versus dual-peak LED LCUs. Acta Medica Marisiensis 2016;62(1):5-14. DOI: 10.1515/amma-2016-0009.

7. Dionysopoulos D, Tolidis K, Gerasimou P. The effect of composition, temperature and post-irradiation curing of bulk fill resin composites on polymerization efficiency. Mater Res 2016;19(2):466-473. DOI: 10.1590/1980-5373-MR-2015-0614.

8. Christensen GJ. Advantages and challenges of bulk fill resins. CR Foundation 2012;5(1):1-6.

9. Leprince JG, Palin WM, Vanacker J, et al. Physico-mechanical characteristics of commercially available bulk- fill composite. J Dent 2014;42(8):993-1000. DOI: 10.1016/j.jdent.2014.05.009.

10. Chesterman J, Jowett A, Gallacher A, et al. Bulk-fill resin-based composite restorative materials: a review. Br Dent J 2017;222(5):337344. DOI: 10.1038/sj.bdj.2017.214.

11. Price RB, Felix CA, Andreou P. Third-generation vs a secondgeneration led curing light: effect on. Knoop microhardness. Compend Contin Educ Dent 2010;31(5):1-9.

12. Ritter AV, Boushell LW, Walter R. Sturdevant's Art and Science of Operative Dentistry, ch. 6 7th ed., St. Louis: Elsevier; 2019.

13. Sakaguchi RL, Power JM. Craig's restorative dental materials. 13th ed., Philadelphia: Elsevier; 2012. pp. 161-181.

14. Pelissier B, Jacquot B, Palin WM, et al. Three generations of LED lights and clinical implications for Optimizing their use. 1: from past to present. Dent Update 2011;38(10):660-670. DOI: 10.12968/ denu.2011.38.10.660. 
15. Gokce K, Ersoy KM, Ozel E, et al. Effect of different light curing systems on surface hardness of composite resins. Balk J Stom 2013;17:75-78.

16. Namoto R, Mc Cabe JF, Nitta K, et al. Relative efficiency of radiation sources for photopolymerization. Odontology 2009;97(2):109-114. DOI: 10.1007/s10266-009-0105-8.

17. Yaman BC, Efes BG, Dorter $C$, et al. The effects of halogen and light emitting diode light curing on the depth of cure and surface microhardness of composite resins. J Conserv Dent 2011;14(2): 136-139. DOI: 10.4103/0972-0707.82613.

18. AlShaafi MM. Factors affecting polymerization of resin-based 5 composites: a literature review. Saudi Dent J 2017;29(2):1-11. DOI: 10.1016/j.sdentj.2017.01.002.

19. Conte G, Panetta M, Mancini M, et al. Curing effectiveness of singlepeak and multi-peak led light curing units on Tpo-containing resin composites with different chromatic characteristics. Oral Implantol 2017;2(2):140-150. DOI: 10.11138/orl/2017.10.2.140.

20. Mikhail SS, Schricker SR, Azer SS, et al. Optical characteristics of contemporary dental composite resin materials. J Dent 2013;41(9):771-778. DOI: 10.1016/j.jdent.2013.07.001.

21. Al-ahdal K, llie N, Silikas N, et al. Polymerization kinetics and impact of post polymerization on degree of conversion of bulk fill resin composite at clinically relevant depth. Dent Mater 2015;31(10): 1207-1213. DOI: 10.1016/j.dental.2015.07.004.

22. Alshali RZ, Silikas N, dan Satterthwaite JD. Degree of conversion of bulk fill compared to conventional resin composites at two time intervals. Dent Mater 2013;29(9):213-217. DOI: 10.1016/ j.dental.2013.05.011.

23. Dickens S, Stansbury J, Choi K, et al. Photopolymerization kinetics of methacrylate dental resins. Macromolecules 2003;36(16):6043-6053. DOI: 10.1021/ma021675k.

24. Sideridou I, Tserki V, Papanastasiou G. Effect of chemical structure on degree of conversion in light-cured dimethacrylate-based dental resins. Biomaterials 2002;23(8):1819-1829. DOI: 10.1016/s01429612(01)00308-8.

25. Papadogiannis D, Tolidis K, Gerasimou P, et al. Viscoelastic properties, creep behavior and degree of conversion of bulk fill composite resins. Dent Mater 2015;31(12):1533-1541. DOI: 10.1016/j.dental.2015. 09.022 .
26. Ilie N, Keßler A, Durner J. Influence of various irradiation processes on the mechanical properties and polymerisation kinetics of bulkfill resin based composites. J Dent 2013;41(8):695-702. DOI: 10.1016/ j.jdent.2013.05.008.

27. Zorzin J, Maier E, Harre S, et al. Bulk-fill resin composites: polymerization properties and extended light curing. Dent Mater 2015;31(3):293-301. DOI: 10.1016/j.dental.2014.12.010.

28. Halvorson R, Erickson R, Davidson C. An energy conversion relationship predictive of conversion profiles and depth of cure for resin-based composite. Operative Dentistry- University Of Washington 2003;28(3):307-314.

29. Ilie N, Hickel R. Resin composite restorative materials. Aust Dent J 2011;56:59-66. DOI: 10.1111/j.1834-7819.2010.01296.x.

30. Flury S, Hayoz S, Peutzfeldt A, et al. Depth of cure of resin composites: is the ISO 4049 method suitable for bulk fill materials? Dent Mater 2012;28(5):521-528. DOI: 10.1016/j.dental.2012.02.002.

31. Thomé T, Steagall Jr,W, Tachibana A, et al. Influence of the distance of the curing light source and composite shade on hardness of two composites. J Appl Oral Sci 2007;15(6):486-491. DOI: 10.1590/s167877572007000600006.

32. Caldas D, Almeida J, Correr-Sobrinho L, et al. Influence of curing tip distance on resin composite Knoop hardness number, using three different light curing units. Operative Dentistry-University Of Washington 2003;28(3):315-320.

33. Silva CM, Dias KR. Compressive strength of esthetic restorative materials polymerized with quartz-tungsten-halogen light and blue LED. Braz Dent J 2009;20(1):54-57. DOI: 10.1590/s010364402009000100009.

34. Mandikose MN, Mcgicney GP, Davis E, et al. A comparison of the wear resistence and hardness of indirect composite resin. J Prosth Dent 2001;85(4):386-395. DOI: 10.1067/mpr.2001.114267.

35. Santos GP, Medeiros IS, Fellows CE, et al. Composite depth of cure obtained with QTH and LED units assessed by microhardness and micro-Raman spectroscopy. Oper Dent 2007;31(1):79-83. DOI: 10.2341/06-26.

36. Ferracane JL. Correlation between hardness and degree of conversion during the setting reaction of unfilled dental restorative resins. Dent Mater 1985;1(1):11-14. DOI: 10.1016/S0109-5641(85)80058-0. 